\title{
Learner's Evaluation in Teaching Learning Process
}

\author{
Dr. Daruri Venugopal
}

Professor, Department of Mathematics, OPJS University, Churu, Rajasthan, India.

\section{To Cite this Article}

Dr. Daruri Venugopal, "Learner's Evaluation in Teaching Learning Process ", International Journal for Modern Trends in Science and Technology, 6(7): 175-180, 2020.

\section{Article Info}

Received on 22-May-2020, Revised on 22-June-2020, Accepted on 25-July-2020, Published on 27-July-2020.

\section{ABSTRACT}

Learner's Evaluation approach we understood the activities and experiences that the learners undergo in order to acquire the desired behavior. The faculty plays an important role in providing learning experiences. Learning experiences involve interaction of students and content with the help of faculty. Learning experience lead to behavior changes among learners. Learner Appraisal ascertaining the extent to which the teaching objectives have been met. The representation of the educational process shows the linking of each element with the other. In learner's evaluation in teaching learning process desired direction and attainment of goals is guided by the educational objectives formulated by the educational Institution, University and the faculty.

KEYWORDS: Appraisal, acquire, attainment, desired direction, educational, interaction, linking.

\section{INTRODUCTION}

Learning activities and experiences that the learners undergo in order to acquire the desired behavior plays an important role in providing learning experience. Learner appraisal ascertains the extent to which the teaching objectives have been met. Learner's evaluation plays an important role in the teaching learning process. In learning evaluation it provides formulation of objectives, designing of learning experiences and assessment of learner performance. Evaluation is one of the most important stages in teaching-learning process. It is inevitable in classroom teaching as it is in all fields of activity when judgments need to be made, however simple or complex the consideration involved. Evaluation helps teachers to make better evaluative judgments. Learners Evaluation consists of achievement test with major objectives of Instructional, Design and Blue print, writing a question, marking scheme, Question wise Analysis, oral test, diagnostic test, Learners achievement progress report, Overall profile of the student.

The major ideologies involved in constructing of achievement test in learning activities are monitoring student's learning and to provide ongoing feedback to both students and faculty during the teaching -learning process and to identity the student's learning difficulties whether persistent or recruitment, to assign grades and to measure whether students possess the pre requisite skills needed to succeed in any unit or whether the students have achieved the objective of the planned instructions.

\section{Achievement Test}

Knowledge objective is considered to be the lowest level of learning whereas understanding, 
application of knowledge in sciences or behavioral sciences are considered higher level of learning. Each subject has a different set of instructional objects. In the subject of Science, Social Sciences, and Mathematics the major objectives are categorized as knowledge, understanding, application and skill. The second major step in planning a test is to make the proper Design. The design specifies weightages to different ideologies like levels of difficulty, units and sub units of the course content, types of questions and instructional objectives. It indicates as to whether there are any options in the question paper, and if so, what their nature in the learning process.

Table 1

Instructional Objectives Outcomes weightage

\begin{tabular}{|c|c|c|c|}
\hline \multicolumn{4}{|c|}{ DESIGN } \\
\hline \multicolumn{2}{|c|}{ SUBJECT:GRAPH THEORY } & & \\
\hline \multicolumn{4}{|c|}{ COURSE : B.TECH } \\
\hline SL.NO & OBJECTIVES & MARKS & $\begin{array}{c}\text { PERCENTAGE } \\
\text { OF MARKS }\end{array}$ \\
\hline 1 & KNOWLEDGE & 25 & 100 \\
\hline 2 & UNDERSTANDING & 25 & 100 \\
\hline 3 & APPLICATION & 25 & 100 \\
\hline \multirow[t]{2}{*}{4} & SKILL & 25 & 100 \\
\hline & TOTAL & 100 & 100 \\
\hline
\end{tabular}

Table 2

Subject Units Weightage

\begin{tabular}{|c|c|c|}
\hline SL.NO & Units and Sub units & Marks \\
\hline 1 & & \\
\hline 2 & & \\
\hline 3 & & \\
\hline 4 & & \\
\hline
\end{tabular}

Table 3

Forms of Questions Weightage

\begin{tabular}{|c|c|c|c|c|}
\hline $\begin{array}{c}\text { SL. } \\
\text { No. }\end{array}$ & $\begin{array}{c}\text { Question } \\
\text { Forms }\end{array}$ & $\begin{array}{c}\text { Marks } \\
\text { allotted } \\
\text { for each } \\
\text { Qn. }\end{array}$ & $\begin{array}{c}\text { Number of } \\
\text { Questions }\end{array}$ & $\begin{array}{c}\text { Total } \\
\text { Marks }\end{array}$ \\
\hline 1 & $\begin{array}{c}\text { Long } \\
\text { Answers }\end{array}$ & & & \\
\hline 2 & $\begin{array}{c}\text { Short } \\
\text { Answers }\end{array}$ & & & \\
\hline 3 & $\begin{array}{c}\text { Very Short } \\
\text { Answers }\end{array}$ & & & \\
\hline
\end{tabular}

Internal questions will be given only in Long Answer Questions only. Illustrated above table is only an approximation. In learner's evaluation policy making as the total time is calculated on the basis, of the number of questions required to be answered and the length of their anticipated answers.

The third major step is to prepare the "Blueprint" of the Curriculum. The decisions, as reflected in the design of the question paper, are presented into action through the well-organizedBlueprint. At this stage that the paper setter confirms as to how many questions are to be set for each different objectives. Further we have to decide under which unit or topic a particulars questions is to be set. In next level we can select various forms of questions. Hence the paper setter decides how all the questions are to be fixed in a particular distribution form over different objectives and content areas so as to obtain the weightages decided in the Design.

Writing of Questions in accordance with the broad parameters set out in the blueprint. We must consider one small block of the blueprint at a time and write out the required questions. For each block of blueprint which is failed in, questions have got to be written one by one. Once it is completed we have all the questions for further necessary requirements laid down in the fixed blueprint. While selecting each small block for writing a question, we can proceed in several ways.

$>$ Either writing all questions belonging to one objective at a time.

$>$ By writing step by step questions for one unit of the syllabus or in the given portion to be covered by the test at a time.

$>$ By taking up questions as given in blueprint according to their form.

Marking Scheme helps prevent inconsistency in judgment. In the marking scheme, possible responses selected for the respective items in the test are structured. The various value points for each question received response are graded and the marks allowed to each value point indicated. The marking scheme of course always provides and includes the scoring key, which is prepared in respect of objective type questions.

The Question wise Analysis helps the paper setter to ensure that there is no imbalance in the question paper. In Analysis process question wise Selection procedure the paper setter will analyze 
each question on various parameters stated in the blueprint.

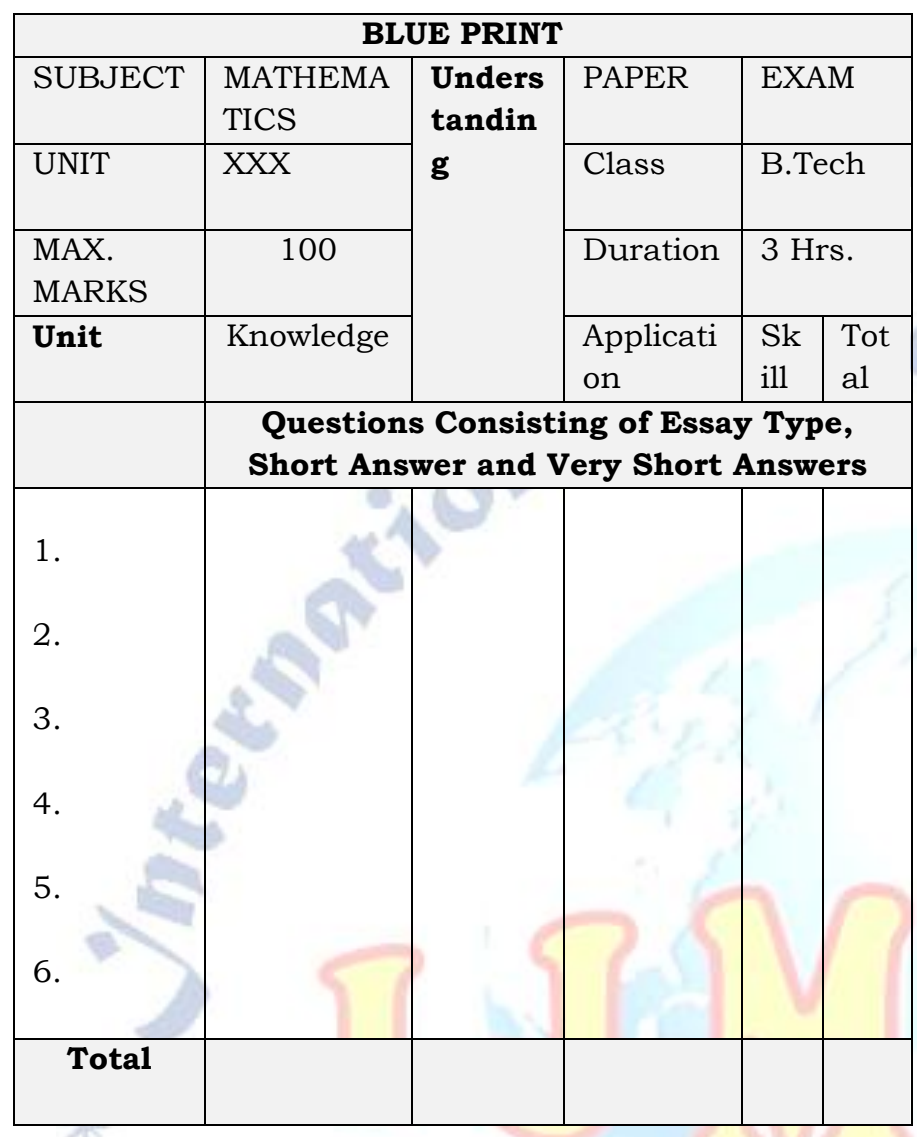

\section{FEATURES OF GOOD MARKING SCHEME}

In respect of long answer or essay type questions, the expected outline answers should be complete and cover all possible or major areas as demanded by the question.

$>$ Clearly indicate each expected point or the parts under the outlined major areas based on Units.

$>$ In general in short answer questions selection a complete answer may be provided with its break-ups where ever necessary along with the break-up of marks.

$>$ Out of the total marks assigned for a question, each point so explained may be assigned marks according to their significance in the answer.

$>$ In evaluation we can observe few situations, apart from the content, different qualities of answer may also matter significantly, particularly in long answer or essay type questions. By logical approach, coherence, it can be selected.

> In Evaluation Scheme of marking needs to be comprehensive enough not to leaves any point unexpected and thus should provide clear guidelines in respect of the break-up of marks over different content points of the answer.

\section{STANDARD ACHIEVEMENT TEST}

A Standard test is one for which policy norms have been established in well design form. A large number of pupils and their respective scores have been given definite expectancy values or norms for given groups of pupils. A norms is an average topical score which measures achievement. Every standardized test has norms. It is prepared by a test observer or specialist according to certain definite rules of standards of construction. The forms of questions in standardized test are generally short answer type or object test items. A particular standardized test serves a particular purpose. The preliminary form of the test contains more items than are to be included in the final test. The preliminary test is revised in the light of investigations and the final form is published for use by Institutional people.

Difference of Faculty made Test and Standardized Test - A faculty made test is intended to measure the outcomes of learning which faculty in particular has in mind. The standardized test is purely for the evaluation and measure the educational outcomes aimed at generally by a number of schools. A faculty made test is not a published test as it is to be used by a faculty for his own institute to measures the attainment of objectives which he himself has laid down for classroom lecture. A published standardized test is prepared to measure the objectives of teaching a subject by a number of Institutions. So all Institutions/Colleges people are consulted and therefore it is more comprehensive.

The standardized tests are more accurate than all the teacher made tests put together because in their constructing much expert thought has been employed. The faculty made tests are not so carefully prepared. The items of faculty made tests are selectively edited. The types of behavioral changes covered are limited in scope. The standardized test can be used by HOD/Academic Concerned Team to compare the achievement of their pupils with that of the pupils of other colleges.

\section{DIAGNOSTIC TEST}

Diagnostic Test is essential to find out the learning difficulties of student during instruction to make the teaching-learning process effective. This can be done by asking use of diagnostic tests. The diagnostic tests in all evaluation systems 
consist of items based on a detailed analysis of theprescribed specific skills involved in successful performance and a study of the most common errors made by students. The test difficulty is low. A good diagnostic test will permit student to demonstrate all aspects of the skills being measured and will pinpoint the types of errors that we made. The following are the few important points that we consider in Diagnostic Tests.

> Diagnostic tests provide any partial information for diagnosing a student's difficulty. Other methods like observation have to be made use of to supplementary and complement this information.

> The diagnostic tests show the repeated errors where a student makes, but they do not indicate the causes of the errors. Some causes can be easily inferred from the type of evaluation error made, or from a student's explanation of how we arrived at the answer.

> While selecting aevaluation test the diagnostic procedures should be evaluated first, in the light of the specific type of information desired.

$>$ Results from diagnostic test, concerning specific learning difficulties approaches to have a low reliability because there are relatively few items measuring each type of error.

$>$ The findings regarding specific strengths and weaknesses for any particular student should be regarded as clues to be verified by other objective evidence and by regular classroom observation.

\section{SCORING A TEST}

The major necessity for extreme care in scoring will alwaysindicated by several studies showing that scoring errors occur with appalling, frequency. Studies shows that extreme care is the need of a good marking scheme. Constant errors can be due to failure to understand scoring directions, with resultant scores which are consistency too low or too high, Variable errors can be due to carelessness in marking, adding, computing, or transcribing scores. We can identify few important points that we can keep in mind while scoring a test are like Order of Scoring, Rescoring and Keeping Records etc.,

$>$ Order of Scoring - with easy test it may be desirable to have one person score all answers to the first question, then to the second, and so on. If, for objective tests for each evaluation separate answer sheets are provided, the scorer may score a given page in all booklets first, then the next page, and it will continue rather than scoring all of one booklet before going on to the next page.

$>$ Rescoring - With a large number of booklets in evaluation to be scored in learners policy marking and sufficient help available, it is always worthwhile to rescore them so as to eliminate repeated errors that otherwise are almost inevitable in a clerical task. Rescoring a sample will always uncovers such an inaccuracy as to maker it desirable to rescore the remainder. In routine some situations if complete rescoring is not possible all the time every fifth or tenth booklet should be rescored to get a rough idea of the distribution frequency and magnitude of scoring errors.

$>$ Keeping Records - As soon as possible after theevaluation tests have been administered, and cross checked the answer sheet should be scored, and the

$>$ scores should be recorded on the permanent records of the educational Institutions. Each teacher

> Usually in Educational Institutions have some type of permanent records for each pupil which provides space for recording standardized test results.

\section{GRADING SYSTEM}

In system of grading, students are classified into a few ability groups or categories according to their level of achievement in an examination. The achievement is defined in the form of numerical or letter grads, each of which denotes a certain level of performance, generally not in absolute terms but in relation to the performance of the whole group. In general Absolute, Comparative grading Systems we can observe in Educational Institutions.

$>$ Absolute Grading - approach involves direct conversion of marks into grades. Whatever be the distribution of marks in a subject, the marks between two fixed points on 0 to 100 Scale would correspond to a given grade.

$>$ Comparative Grading - This involves conversion of marks into grades on the basis of rank order or percentage. In such type of conditions the distribution of marks is taken into consideration while considering the range of marks corresponding to different grades. 
$>$ Advantages - Grades in different subjects in an examination provide a meaningful profile of the achievement of a student. Unlike marks, we can easily find out in which test subject or paper the performance is outstanding, good fair or poor. With secured marks, any onecan arrive at such inference only on knowing what the range, average and dispersion are of the marks in the different course subjects.

$>$ There is a good and necessary comparability among subjects when grades are used. When there is a choice of subjects, student need not avoid the subjects which are considered low scoring.

$>$ Even with a so called low scoring course subject, the proportion of students getting a grade would be nearly the same as in a so called high scoring course subject.

> Grading based on relative marks that we have in our usually notation. These grades

are expressed in the form of letters $\mathrm{A}, \mathrm{B}, \mathrm{C}, \mathrm{D}, \ldots$ etc.

$>$ With the same uniform pattern being adopted for all subjects, grading would provides better comparability of the results of different years in the same subject.

\section{QUESTION BANK EVALUATION}

The question bank is designed to fulfill certain predetermined purposes. Its efficient functioning, demands co-operative enterprises. Its focus is on improvement of the teaching learning approach method. Question bank is a planned library of test items to be used by evaluators teacher,/faculty members and students in partial fulfillment of the requirement of the teaching learning process. A question bank can serve two purposes to enrich the instructional side as well as to judge the students growth in terms of instructional efforts. On the instructional side, questions can be sued by faculty at the protesting stage.

A pool of test questions on a unit or a topic can be used for formative evaluation which is in integral part of teaching. Such a group of questions can also be made use of, in preparing course question papers at the end of term for summative evaluation. Questions can also be used for diagnosis of the student difficulties.

\section{ORAL TEST EVALUATION}

Oral examination in any subject is a time honored form of measurement. It is still used at the university level for thesis examinations at the early childhood level for content examinations, and post level for occupational placement examination. In theroutine classical form of the subjective oral examination, the question is presented orally to the examinee and is responded to in like manner. However, two alternative forms of responses to orally presented problems should also be considered because they have elements in common with the more traditional oral response form.

In regular evaluation process there are three approaches like Oral Response Test, Written Response Test and Oral Performance Test.

$>$ Oral Response Test - In evaluation system the oral response form of the oral subjective examination the examiner present the question using the spoken word and the examinee responds in the same manner. This type of test is considered by many to be the only legitimate form of oral examination.

$>$ Written Response Test - In the written response approach form of the oralevaluation examination, the questions are presented by the examiner by the use of the spoken word and are answered in writing by the examinee. The written response test can be thought of as falling somewhere between the classical oral examination and the written examination. The written response form of the evaluation oral examination is used by the classroom faculty more often than the oral response form. Since it can be used to examine several students simultaneously, rather than only one at a time, many of the defects of the oral response test are less significant for this test form.

$>$ Oral Performance Test - In the performance test, the student is orally presented with a task to carry out, and student's skill in executing is assessed.In general evaluation many instructional objectives which cannot be measured by written test evaluation process are amenable to measurement by oral examinations of the performance variety. In Learners evaluation process Oral examinations have the same level of limitations as essay examinations - poor sampling of subject content, great consumption of time duration and low reliability.

\section{Conclusion}

In Educational Policy making knowledge objective is considered to be the lowest level of 
learning. Application of knowledge in sciences or behavioral sciences is considered higher level of learning. The necessity for extreme care in scoring has been indicated by several studies showing that scoring errors occur with applying frequency. Grades in different course subjects in an examination provide a meaningful profile of the nachievement of a student. The written response form of the oral examination is used by the classroom teacher/faculty more often than the oral-response form.

\section{ACKNOWLEDGMenT}

I am very much thankful to the Prof.Dr.Dalel Singh, Vice-Chancellor, Dean School of Science, Microbiology \& Agriculture and The Registrar of OPJS University for their contribution in publication work. I am extremelygrateful to Prof.V.Kannan Former Pro-Vice-Chancellor of University of Hyderabad, who unconditionally gave me his valuable time and guidance in Research Activities. I wish to show my gratitude to my Academic Guru Dr.G.Manohar Reddy Garu and Dr.N. Goutham Rao Garu Management of Swamy Vivekananda Educational Truest, Hyderabad for their motivational thoughts and Support in Academics and Research activities.

\section{REFERENCES}

[1] Atkiin, J.M.(1992). Teaching as research: An essayTeaching and Teacher Educatin8(4),381-390.

[2] Asp,E.(1998). Assessing student learning: New rules, new realities(17-46). Arlington, VA: Educational Research Service.

[3] Aschbacher, P.R.(1993). Research Article - Issues in innovative assessment for classroom practice.

[4] Ames,C.(1992). Classrooms: Goals,structures, and student motivational. Journal of Educational Psychology,84(3),261-271.

[5] Baron,J.B.(1991). Applied Measurement in Eduction,4(4), 308-318.

[6] Sampling Theory and Execution of Sample Surveys in Statistical Organizations by Dr.Daruri Venugopal Research paper, IRJMETS, Page:893-897.

[7] Educational evaluation and Analysis of Statistical Techniques, IJREAM-UGC Journal, Dr.Daruri Venugopal,Vo.06,Issue-02,May-2020.

[8] Baxter, G.P.,Elder, A.D., \& Glaser, R.(1996). Knowledge-based cognition and learnersperformance assessment in the science classroom.

[9] Network for Education in Emergencies (2004). From www.ineesite.org/minimum_standards/MSEE_report.pdf

[10] National Council of Educational Research and Training.(1988). National Curriculum for Secondary Education: NCERT,New Delhi 